\title{
DETECTION OF FREE AMINO ACIDS AND ISOENCYMES FROM THE HAEMOLYMPH OF THE MATURE LARVAL IMSTAR OF SILKWORM, BOMBYX.MORI L.
}

Eid, M. A.; S. A. Al-Otaibi; S. A. S. EL-Maasarawy and M.R. Abo- AL-Ela

Dept. Economic Entomology and Pesticides, Fac. Agric. Cairo Univ. Giza, Egypt.

\begin{abstract}
Seventeen different free amino acids were detected from haemolymph of the mature larval instar of Bombyx mori L. male and female. Three amino acids (proline, glycine and glutamine) represent 77.1 and $69.18 \%$ of all pool amino acids found in females and males haemolymph, respectively. Proline was the most predominated free amino acids in males $(45.81 \mu \mathrm{mole} / \mathrm{ml})$ and females $(55.25 \mu \mathrm{mole} / \mathrm{ml})$. Glycine came second with a concentration of 27.58 and $30.25 \mu \mathrm{mole} / \mathrm{ml}$ in males and females, respectively. The multiple forms of the isozyme glucose-6-phosphate dehydrogenase (G-6-PDH) in mature larval instar haemolymph of both sexes of $B$. mori are pentameric, while that of the isoenzyme alkaline phosphatase (ALP) are trimeric. Three isoenzyme bands of isoenzyme G-6-PDH are characteristic of males (RF. 0.10, 0.043 and 0.068) and three other bands (RF. 0.05, 0.49 and 0.88) are characteristic of females. For the isoenzyme ALP has a band with RF. 0.051 characterizing of males while the band which had RF. 0.58 characterizes females.
\end{abstract}

\section{INTRODUCTION}

The silkworm, Bombyx mori L., has a high economic importance in sericulture. Fibroins are the protein substance excreted by various species of Arthropoda from special glands and stored there in solution perior to extrusion to form filaments. These filaments were embedded in a globular protein; sericin. The fibroin of $B$. mori is unusual in its amino acid composition and it was given by Sasaki and Noda (1973). The fibroins that provide the structural basis of the cocoons of different insects species perform essentially the same function for each ( protection from predators, extremes of temperature, physical shock, microbiological attack and the general rigors of climate). It is remarkable that the variation in amino acid composition that has been found is perfectly compatible with this function (Agosin, 1978).

Metabolism in insects is limited by three ways; the glycolysis, the tricarboxylic acids cycle and the pentose cycle. These cycles are controlled by dehydrogenase enzymes which play many important roles in insect body and their relative activities may be related to the function and energy-yielding demands of the tissue (Horiey, 1967). Studies have shown that differential isozyme expression is the result of different synthetic rates (Davis and Mclntyre, 1998). The isozyme alkaline phosphatase (ALP) plays an important role in desorption of metabolites generally and sugars in particular (Sridhara and Bhat, 1963 and Rousell, 1971). This may indicate its important role in 
Eid, M.A. et al.

transportation of materials like glucose through the intestinal wall. This work is presented to through more light on amino acid concentration and detection of isoenzymes; glucose-6-phosphate dehydrogenase (G-6-PDH) and alkaline phosphatase (ALP) in last larval instar of $B$. mori haemolymph.

\section{MATERIALS AND METHODS}

\section{1- Determination of free amino acids:}

The haemolymph of B.mori larvae were collected from punctured proabdominal legs of thirty healthy mature larvae of both sexes in sterile tubes with a small crystal of phenylthiourea to prevent melanization of the sample. Three $\mathrm{ml}$ of haemolymph sample was added to $10 \mathrm{ml}$ ethanol at room temperature, then the precipitated protein was filtered and evaporated to dryness at $40{ }^{\circ} \mathrm{C}$. The residue was dissolved in $3 \mathrm{ml}$ water. $0.5 \mathrm{ml}$ dansylchloride solution was added to $1 \mathrm{ml}$ of the conditioned sample and adprested to $\mathrm{pH} 8.0$ with the prepared sodium bicarbonate solution. For the derivatization-reaction the solution is placed in the dark at room temperature for 16 hours. The reaction solution was transferred with acetone : water ( 7 : 3) in $10 \mathrm{ml}$ measuring flask and filled up. For the calibration standard, $1 \mathrm{mg} / \mathrm{ml}$ of standard mixture dissolved in water. $1 \mathrm{ml}$ of dansylchloride solution was added to $1 \mathrm{ml}$ amino acid and filled up to $100 \mathrm{ml}$ with acetone : water $(7: 3)$ after derivatization reaction. Concentration of the standard solution in $10 \mu \mathrm{g} /$ $\mu$ l.

Sample application: S1 U1, S2 U1, S3 U1, S4 U2, S5 U2, S6 U2.

$\mathrm{S} 1=1 \mu \mathrm{l}=10 \mathrm{ng}$ absolute, $\mathrm{S} 2=2 \mu \mathrm{l}=20 \mathrm{ng}$ absolute, $\mathrm{S} 3=3 \mu \mathrm{l}=30 \mathrm{ng}$ absolute, $\mathrm{S} 4=4 \mu \mathrm{l}=40 \mathrm{ng}$ absolute, $\mathrm{S} 5=5 \mu \mathrm{l}=50 \mathrm{ng}$ absolute, $\mathrm{U} 1=6 \mu \mathrm{l}$ (Sample diluted $1: 10$ ), U2 = $5 \mu \mathrm{l}, \mathrm{S}=$ Standard, $\mathrm{U}=$ Sample.

Developing the plates with solvents according to the method adopted by Das and Sawant (1993). Two types of solvents were incorporated in the separation of amino acids and they determine the retention factor values ( $\mathrm{hRf}$ value). Solvent 1 is chloroform : propinic acid : ethyl acetate $(23: 6: 4)$ for the separation of Dansyl-L-arginine, Dansyl-L-lycine, Dansyl-L-cystine, Dansyl-Laspartic acid, Dansyl-L-serine, Dansyl-L-threonine, Dansyl-L-glutamic acid, Dansyl-L-glutamine. Solvent 2 is chloroform : acetone : propinic acid (24:10 : 5) for the separation of Dansyl-L-tyrosine, Dansyl-L-alanine, Dansyl-Lmethionine, Dansyl-L-valine, Dansyl-L-proline, Dansyl-L-phenylalanine, Dansyl-L-isoleucine, Dansyl-L-leucine.

CAMAG HPTLC sanner II with Lab Data system and CATS evaluation software was used for densitometic evaluation.

\section{Isoenzymes assay:}

The enzymes, glucose-6-phosphate dehydrogenase (G-6-PDH) and alkaline phosphatase (ALP) in blood supernatants were separated by discontinuous polyacrylamide gel electrophoresis according to Maurer (1968) and were assayed and detected by the methods of Shaw and Parsad (1970). Enzymatic protein bands were designated according to the system 
nomenclature proposed by Shaklee et al. (1990). Electrophoresis was carried out conveniently in discontinuous polyacrylamide gels (stacking and tracking gels). An amount of $50 \mu \mathrm{l}$ of clear supernatant of the blood for each sample was mixed with $20 \mu \mathrm{l}$ of protein dye (1\% bromophenol blue) and $20 \mu \mathrm{l}$ of $2 \%$ sucrose. $30 \mu \mathrm{l}$ of the mixture per gel slot was used to be applied per each sample for isoenzymes electrophoresis. After electrophoresis, the gel was transferred into a staining solution $(50-70 \mathrm{ml})$ which was then replaced by a destaining mixture of methanol, acetic acid and water (5: 1: $5 \mathrm{v} / \mathrm{v} / \mathrm{v})$. A potential gradient of $20 \mathrm{v} / \mathrm{cm}$ across the gel was applied for 4 hours at $8 \stackrel{\circ}{\circ}$.

\section{RESULTS AND DISCUSSION}

\section{Haemolymph free amino acids}

Seventeen different free amino acids were detected from haemolymph of the last larval instar of Bombyx mori L.. male and female (Table 1). These amino acids were arranged in 4 groups; I, II, III, IV on the basis of polar versus non-polar character i. e., polar and charged, polar and uncharged, non polar and those with unique properties (Karp, 1969).

Group I contained aspartic, glutamine, lysine, arginine and histidine. The concentration of these acids were 40.264 and $28.154 \mu \mathrm{mole} / \mathrm{ml}$ in the last larval instar of male's and female's haemolymph, respectively. The amino acid glutamine was the highest $(23.404 \mu \mathrm{mole} / \mathrm{ml}$ in males and $17.080 \mu$ mole/ $\mathrm{ml}$ in females). The most predominant amino acids of this group are glutamine followed by histidine, aspartic acid, arginine and lysine in both sexes. The members of this polar and changed amino acids represent $28.95 \%$ of the total amino acids present in male's haemolymph and $21.14 \%$ in female's haemolymph.

Group II contained serine, threonine, and tyrosine. The concentration of these acids was 11.950 and $7.752 \mu \mathrm{mole} / \mathrm{ml}$ in the last larval instar of male's and female's haemolymph, respectively. Their percentages were 8.33 and $5.07 \%$ of total amino acids in male's and female's haemolymph, respectively. The most abundant amino acids in this group were threonine followed by serine and tyrosine in both sexes.

Group III contained six free amino acids i. e., phenylalanine, methionine, leucine, isoleucine, alanine and valine. They constitute 8.33 and $6.99 \%$ of the total pool of the last larval instar amino acids haemolymph of males and females, respectively. The concentrations of the individual amino acids ranged between 2.655 and $0.821 \mu$ mole/ $\mathrm{ml}$ in males while it ranged between 2.345 and $0.741 \mu \mathrm{mole} / \mathrm{ml}$ in females.

Group IV includes proline, glycine and cystine. They have unique properties that separate them from the other amino acids. The $\mathrm{R}$ group of glycine consist of only a hydrogen atom. Proline is unique in having its $\alpha$ amino group as part of a ring (making it an amino acid). Cystine contains a reactive sulphydral (-SH) group and is often present covalently linked to another cystine residue as a disulphide (-SS-) bridge. Disulphide bridges often form between two cystines that are distant from one another in the polypeptides backbone or even in two separate polypeptides. This group 
Eid, M.A. et al.

constituted 54.37 and $66.03 \%$ of the total pool of the last larval instar amino acids haemolymph of males and females, respectively.

When these amino acids were arranged according to their concentration in haemolymph, four groups were obtained as indicated in Table (2). The first group contains amino acids with concentrations higher than $10 \mu \mathrm{mole} / \mathrm{ml}$ ( 3 amino acids for both sexes) while the second group includes concentrations lower than 10 to $5 \mu$ mole/ ml (2 amino acids in both sexes). The third group has concentrations lower than 5 to $1 \mu \mathrm{mole} / \mathrm{ml}(10$ amino acids in males and 9 in females) but the last group includes concentrations are less than $1 \mu \mathrm{mole} / \mathrm{ml}$ ( 2 amino acids in males and 3 in females).

Table (1). Free amino acids concentrations $(\mu \mathrm{mole} / \mathrm{ml})$ in haemolymph of $B$. mori mature larval instar.

\begin{tabular}{|c|c|c|c|}
\hline \multirow{2}{*}{$\begin{array}{l}\text { Groups } \\
\text { acids }\end{array}$} & \multirow{2}{*}{ Amino acids } & \multicolumn{2}{|c|}{ Free amino acids $(\mu \mathrm{mole} / \mathrm{ml})$} \\
\hline & & Males & Females \\
\hline \multirow{6}{*}{$\begin{array}{l}\text { Group I } \\
\text { Polar and charged }\end{array}$} & (A) Glutamine & 23.404 & 17.080 \\
\hline & (B) Histidine & 7.676 & 4.505 \\
\hline & (A) Aspartic acid & 3.964 & 2.326 \\
\hline & (B) Arginine & 3.254 & 2.256 \\
\hline & (B) Lysine (E) & 1.966 & 1.987 \\
\hline & Total percentage & 40.264 & 28.154 \\
\hline \multirow{4}{*}{$\begin{array}{l}\text { Group II } \\
\text { Polar and uncharged }\end{array}$} & Threonine (E) & 4.050 & 2.377 \\
\hline & Serine & 6.551 & 4.499 \\
\hline & Tyrosine & 0.989 & 0.876 \\
\hline & Total percentage & 11.590 & 7.752 \\
\hline \multirow{7}{*}{$\begin{array}{l}\text { Group III } \\
\text { Non polar }\end{array}$} & (N) Alanine & 1.245 & 1.103 \\
\hline & (N) Valine (E) & 0.821 & 0.741 \\
\hline & $(\mathrm{N})$ leucine $(\mathrm{E})$ & 2.541 & 2.222 \\
\hline & $(\mathrm{N})$ Isoleucine $(\mathrm{E})$ & 1.810 & 0.813 \\
\hline & (N) Methionine (E) & 2.513 & 2.082 \\
\hline & (N) Phenylalanine (E) & 2.655 & 2.345 \\
\hline & Total percentage & 11585 & 9.306 \\
\hline \multirow{5}{*}{$\begin{array}{l}\text { Group } 1 \\
\text { R-group with unique } \\
\text { properties }\end{array}$} & (N) Proline & 27.578 & 30.251 \\
\hline & Glycine (E) & 2.220 & 2.446 \\
\hline & (N) Cystine & 45.814 & 55.254 \\
\hline & Total percentage & 75.612 & 87.951 \\
\hline & Total amino acid pool & 139.051 & 133.163 \\
\hline
\end{tabular}

A = Acidic, N = Neutral, B = Basic, E = Essential amino acid 
Table (2). Total free amino acids ( $\mu \mathrm{mole} / \mathrm{ml}$ ) in haemolymph of $B$. mori mature larval instar according to their concentration.

\begin{tabular}{|c|c|c|c|c|}
\hline \multirow{2}{*}{\begin{tabular}{|l|} 
Amino acid \\
groups
\end{tabular}} & \multicolumn{2}{|c|}{ Males } & \multicolumn{2}{|c|}{ Females } \\
\hline & Amino acid & Concentration & Amino acid & Concentration \\
\hline \multirow{4}{*}{$\begin{array}{l}\text { Group I } \\
\text { Concentration > } \\
10 \mu \text { mole/ ml }\end{array}$} & Proline & 45.814 & Proline & 55.254 \\
\hline & Glycine & 27.578 & Glycine & 30.251 \\
\hline & Glutamine & 23.404 & Glutamine & 17.080 \\
\hline & Total & 96.796 & Total & 102.585 \\
\hline \multirow{3}{*}{$\begin{array}{l}\text { Group II } \\
\text { Concentration < } \\
10 \text { to } 4.1 \mu \\
\text { mole/ } \mathrm{ml} \\
\end{array}$} & Histidine & 7.676 & Histidine & 4.505 \\
\hline & Threonine & 6.551 & Threonine & 4.499 \\
\hline & Total & 14.227 & Total & 9.004 \\
\hline \multirow{11}{*}{$\begin{array}{l}\text { Group III } \\
\text { Concentration < } \\
4.1 \text { to } 1 \mu \text { molel } \\
\mathrm{ml}\end{array}$} & Aspartic acid & 3.964 & Aspartic acid & 2.326 \\
\hline & Serine & 4.050 & Serine & 2.377 \\
\hline & Aginine & 3.254 & Aginine & 2.256 \\
\hline & Alanine & 1.254 & Alanine & 1.103 \\
\hline & Methionine & 2.513 & Methionine & 2.084 \\
\hline & Cyctine & 2.220 & Cyctine & 2.446 \\
\hline & Isoleucine & 1.012 & leucine & 2.222 \\
\hline & leucine & 2.541 & Phenylalanine & 2.345 \\
\hline & Phenylalanine & 2.655 & Lysine & 1.987 \\
\hline & Lysine & 1.966 & ------ & ------ \\
\hline & Total & 25.420 & Total & 19.104 \\
\hline \multirow{4}{*}{$\begin{array}{l}\text { Group IV } \\
\text { Concentration < } \\
1 \mu \text { mole/ ml }\end{array}$} & Tyrosine & 0.989 & Tyrosine & 0.876 \\
\hline & Valin & 0.821 & Valin & 0.741 \\
\hline & $\begin{array}{l}----- \\
\end{array}$ & $\begin{array}{l}---- \\
\end{array}$ & Isoleucine & 0.813 \\
\hline & Total & 1.810 & Total & 2.430 \\
\hline Total pool & \multicolumn{2}{|c|}{138.253} & \multicolumn{2}{|c|}{133.123} \\
\hline
\end{tabular}

\section{Isoenzymes:}

The isoenzymes were detected by electrophoresis. The number of recorded bands for glucose-6-phosphate dehydrogenase (G-6-PDH) in last larval instar haemolymph of both sexes of $B$. mori are listed in Table (3) and the electrophoretic patternswere shown in figure (1).

This isoenzyme showed 5 bands in both males and females but only bands which have R.F. 0.31 and 0.68 were common inboth sexes. Bands with R.F $0.10,0.43$ and 0.96 were found to be characteristic for males while bands with R.F $0.053,0.49$ and 0.88 are characteristic for females. The present results show that females last larval instar have higher enzymatic activity of G-6-PDH than in males, which may suggest that the pentose cycle accelerates the metabolic process of glucose in females more than in males. The multiple forms of isozyme G-6-PDH in the haemolymph of the last larval instar of $B$. mori are pentameric in both sexes. This enzyme appears to be the predominated key enzyme for the proceeding of the pentose metabolism in insects, and it is mainly active in the fat body (Horiey, 1967).

Three protein bands have been observed for the isozyme alkaline phosphatase (ALP) in males and females ( Table, 4 and figure, 2). The band which have R.F 0.51 is characteristic to males while band which have R.F 
Eid, M.A. et al.

0.58 is representative for females. Bands with R.F 0.27 and 0.83 are are common and shared in males and females.

The results show that females last larval instar have higher enzymatic activity of ALP than in males The multiple forms of isozyme ALP in the haemolymph of the last larval instar of $B$. mori are trimeric in both sexes.

Table (3). Activities of glucose-6-phosphate dehydrogenase (G-6-PDH) in haemolymph of $5^{\text {th }}$ instar larvae of both sexes of $B$. mori.

\begin{tabular}{|c|c|c|c|c|}
\hline \multirow{2}{*}{ Bands } & \multicolumn{2}{|c|}{ Males } & \multicolumn{2}{|c|}{ Females } \\
\hline & R.F & $\%$ amount & R.F & $\%$ amount \\
\hline 1 & - & - & 0.053 & 23.1 \\
\hline 2 & 0.10 & 18.8 & - & - \\
\hline 3 & 0.31 & 18.3 & 0.31 & 22.2 \\
\hline 4 & 0.43 & 17.8 & - & - \\
\hline 5 & - & - & 0.49 & 16.8 \\
\hline 6 & 0.68 & 22.3 & 0.68 & 19 \\
\hline 7 & - & - & 0.88 & 18.8 \\
\hline 8 & 0.94 & 22.6 & - & - \\
\hline Sum & & 99.9 & & 99.9 \\
\hline In lane & \multicolumn{2}{|c|}{100} & \multicolumn{2}{|c|}{100} \\
\hline
\end{tabular}

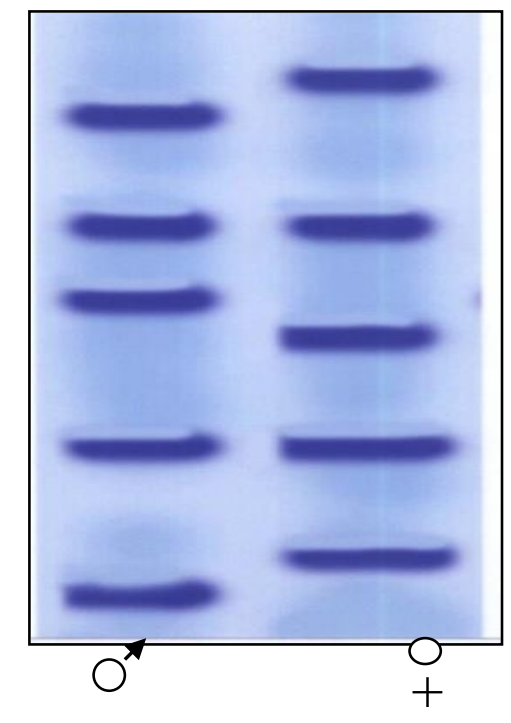

Fig. 1. Electrophoretic pattern of glucose-6-phosphate dehydrogenase isozyme in (G-6-PDH) in haemolymph of $5^{\text {th }}$ instar larvae of both sexes of $B$. mori. 
Table (4). Activities of alkaline phosphatase (ALP) in haemolymph of $5^{\text {th }}$ instar larvae of both sexes of $B$. mori.

\begin{tabular}{|c|c|c|c|c|}
\hline \multirow{2}{*}{ Bands } & \multicolumn{2}{|c|}{ Males } & \multicolumn{2}{c|}{ Females } \\
\cline { 2 - 5 } & R.F & \% amount & R.F & \% amount \\
\hline 1 & 0.27 & 30.9 & 0.27 & 27.7 \\
\hline 2 & 0.51 & 31.1 & - & - \\
\hline 3 & - & - & 0.58 & 19.2 \\
\hline 4 & 0.83 & 38 & 0.83 & 53 \\
\hline Sum & \multicolumn{2}{|c|}{100} & 100 & \multicolumn{2}{c}{100} \\
\hline In lane & \multicolumn{2}{|c}{} \\
\hline
\end{tabular}

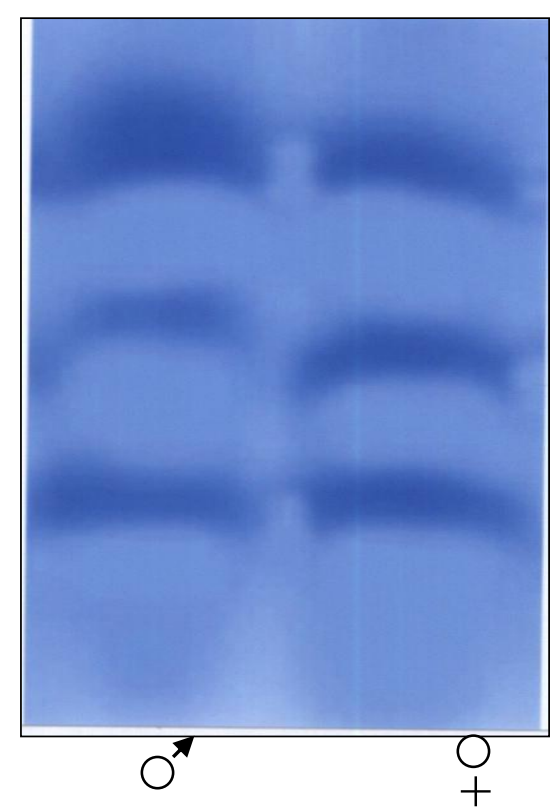

Fig.2. Electrophoretic pattern of alkaline phosphatase isozyme (ALP) in haemolymph of $5^{\text {th }}$ instar larvae of both sexes of $B$. mori.

\section{REFERENCES}

Agosin, M. (1978). Functional role of protein. In" Biochemistry of insects" (M. Rockstein, ed. ), pp: $94-144$. Academic press. New York.

Davis, M. B. and R. J. Mclntyre(1998). A genetic analysis of the $\alpha$ glycerophosphate oxidase locus in Drosophila melanogaster. Genetic, 120: 755 - 766 . 
Das, B. and S. Sawant (1993). Quantitative HPTLC analysis of dansyl amino acids. JPC. Journal of planar chromatography, modern TLC, 6(4):294295.

Horiey, Y. (1967). Dehydrogenase in carbohydrate metabolism in larvae of Bombyx mori. J. Insect Physiology, 13: 1163 - 1175.

Karp, G. (1966). Cell and molecular biology concepts and experiments .(Eds.Jon wiley and sons).inc. New York .pp.54-55.

Maurer, R. (1968). Disk-elektrophrese. Wde Gruyter and Co., Berlin, 222 pp.

Rousell, P. G. (1973). Acid and alkaline phosphatase activity during pupal and adult stages of the face fly, Musca autumnalis (D.). J. Ga. Entomol. Soc., 6: $116-122$.

Sasaki,T. and H. Noda (1973). Studies on silk fibroin of Bombyx mori directly extracted from the silk gland. 1. Molecular weight determination in guanidine hydrochloride or urea solutions.

J. Biochem. Biophys. Acta., 310(1):76-90.

Shaw, C. R. and R. Parsad (1970). Starch gel electrophoresis of enzymes: A compilation of recipes. Biochem. Genet., 4: $297-329$.

Shaklee, J. B.; F. W. Allendorf; D. C. Morizot and G. S. Whitt (1990). Gene nomenclature for protein-coding loci in fish. Trans. Amer. Fish Sx., 119: $2-15$.

Sridhara, S. and J. V. Bhatt (1963). Alkaline and acid phosphatases of the silkworm, Bombyx mori L. J. Insect physiology, 9: 693-701.

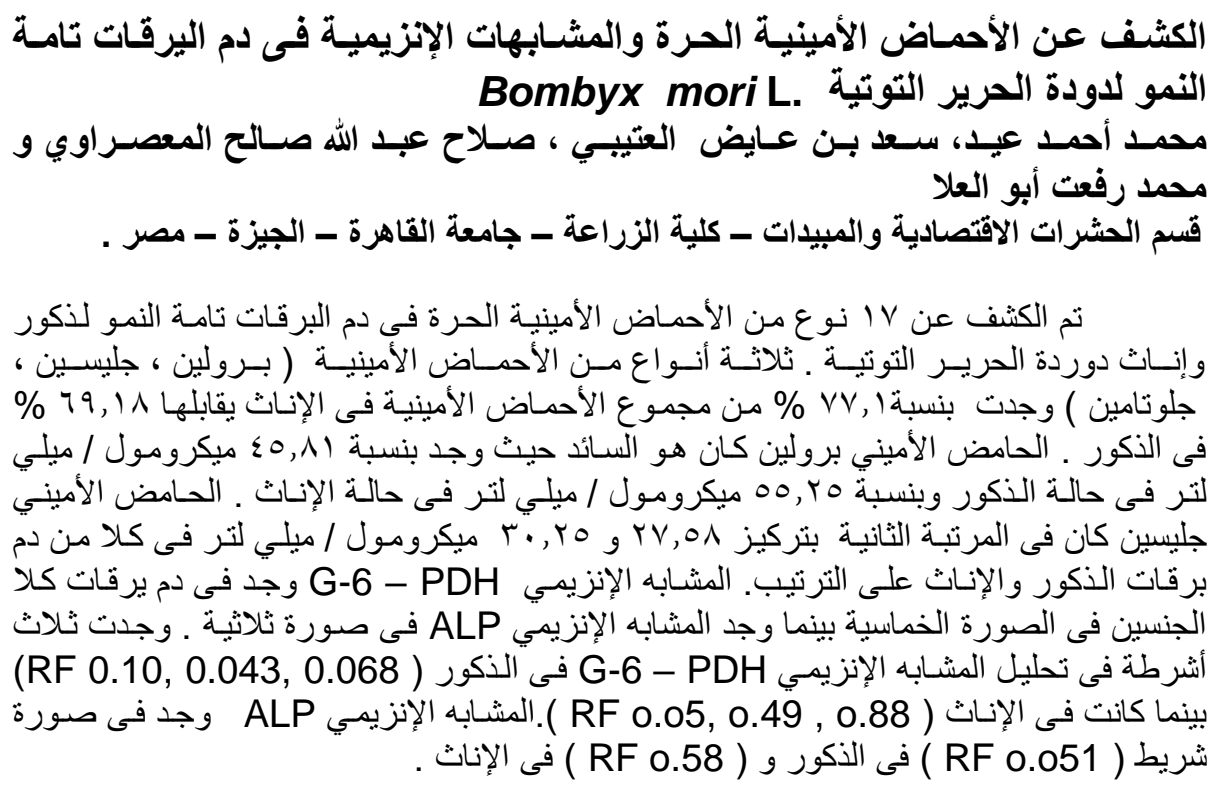


J. Agric. Sci. Mansoura Univ., 33 (3), March, 2008

2253

2254

2255

2256

2257

2258

2259

2260 